\title{
Cultivation Path of Innovation and Entrepreneurship Talents for Cross-border Electronic Commerce under the Background of "Internet Plus"
}

\author{
Lingyan Meng \\ Department of Economic Management \\ Jining University \\ Qufu, Shandong, 273115, China
}

\begin{abstract}
The development of cross-border electronic commerce industry is changing with each passing day. Exploring the cultivation path of innovation and entrepreneurship talents of cross-border electronic commerce is an important topic for current higher education. Several analytical research methods such as field research, literature research, qualitative analysis and expert interviews are used to reveal outstanding problems existing in innovation and entrepreneurship talents cultivation of cross-border electronic commerce in colleges and universities, and the cultivation path of innovation and entrepreneurship talents of cross-border electronic commerce is explored from four dimensions, i.e., teaching team, curriculum design, practical teaching and entrepreneurial incubator. Talents cultivation in colleges and universities should take market demand as guidance and use construction of double-qualified teaching team, modular curriculum system, five-tier progressive practice teaching network and entrepreneurial incubator base as core means to strengthen school-enterprise collaboration and integration of production and education and to break through bottleneck constraints of innovation and entrepreneurship competency cultivation.
\end{abstract}

Keywords-Cross-border electronic commerce; Innovation and entrepreneurship; Practice teaching; Teaching team; Curriculum system

\section{INTRODUCTION}

Under the background of "Internet plus", the cross-border electronic commerce industry has developed rapidly. At present, there are more than 5,000 cross-border electronic commerce enterprises in China, and nearly 300,000 enterprises are engaging in cross-border electronic commerce. According to Ai Media consulting data, the transaction volume of cross-border electronic commerce in Chins reached 9.1 trillion Yuan in 2018, and is expected to reach 10.8 trillion Yuan in 2019. The transaction volume of cross-border electronic commerce in China will account for more than $37 \%$ of total foreign trade in $2020^{[1]}$. Cross-border electronic commerce has entered the stage of industrial collaboration and service intensification, showing multi-regional, multi-categorized and premium development trends, which becomes a new engine for China's foreign trade growth and drives transformation and upgrading of traditional enterprises.

Demand for professional talents of cross-border electronic commerce industry is becoming more and more urgent, while talents supplied by colleges and universities and industry demand are seriously misplaced. Problems of graduates' unskillful operation for cross-border electronic commerce, weak awareness of team cooperation and weak innovation and entrepreneurship competency are highlighted. How to improve professional teaching system of cross-border electronic commerce, explore new modes of innovation and entrepreneurship education for cross-border electronic commerce, cultivate and stimulate college students' innovation consciousness and entrepreneurial spirit, and improve students' competence of innovation and entrepreneurship have become realistic tasks of education and teaching reform in colleges and universities.

\section{Main PRoblems Existing IN THE CULtivation OF INNOVATION AND ENTREPRENEURSHIP TALENTS OF CROSS-BORDER ELECTRONIC COMMERCE}

\section{A. Insufficient reserve of professional teachers}

Development of students requires strong teaching team resources as important support. Since cross-border electronic commerce is an emerging major, its professional teachers mostly come from international trade, electronic commerce and business English majors. Therefore, their professional knowledge reserves mostly come from fragmented knowledge in books and networks, their theoretical system is imperfect and their knowledge structure is updated slowly. The situation of teaching while learning is very common and teachers are relatively unfamiliar with entrepreneurial cultivation. At the same time, teachers lack the basic motivation to engage in this work and are unable to meet the needs of cultivating students' innovation and entrepreneurship competency. However, lecture contents can't reflect the development frontier of cross-border 
electronic commerce professional disciplines. Teachers are not good at grasping practical teaching links, and it lags behind enterprise development practice. The gap between skills teaching and industry requirements directly leads to misplacement between supply and demand of talents in the cross-border electronic commerce industry. Double-qualified teachers who understand professional theories and have industry background as well as cross-border electronic commerce practical experience are scarce, which cannot provide strong team support for innovation and entrepreneurship talents cultivation of cross-border electronic commerce. It is not only caused by teacher's own reasons, but also by the system, incentives and policy guidance.

\section{B. The detachment between professional curriculum system and actual post requirements}

The construction of cross-border electronic commerce majors is still in the stage of exploration and gradual improvement. Talents cultivation program cannot reflect changes in job requirements in a timely manner, cultivation objectives lack pertinence and effectiveness and matching extent between professional curriculum arrangement and post requirements is low, which lacks systematicness and speciality and can't reflect regional characteristics and industrial characteristics. Time allocation in theoretical teaching, experimental training and concentrated practical teaching is not reasonable. In the classroom teaching, task-driven teaching method and scenario simulation teaching method are not widely applied, which makes it difficult for graduates majored in cross-border electronic commerce to meet actual post requirements of different categories, and the contradiction between supply and demand of talents has intensified.

\section{Lagging construction of practical teaching system}

The lack of practical teaching resources is particularly prominent in the construction of cross-border electronic commerce. The construction of cross-border electronic commerce internship bases in colleges and universities cannot meet the needs of the cognitive practice, professional practice and graduation practice of professional talents. The price of simulation training software is high, and the construction of a simulation training base needs a long period of 2-3 years from declaration, approval, bidding and procurement to the completion of construction. The cross-border electronic commerce industry is developing fast, so the simple training courses cannot allow students to understand the latest development in the industry and requirements for vocational skills development. In terms of practical operation, cross-border electronic commerce platforms such as Aliexpress, Wish, Amazon and other platforms have successively adopted the form of charging and company registration, which restricts students' cross-border electronic commerce operations and online entrepreneurial activities. Influenced by various restrictions such as capital, supply chain and social resources, students' entrepreneurial behavior of cross-border electronic commerce is far from the expected effect.

\section{Lagging development of innovation and entrepreneurship incubator base in colleges and universities}

The construction and development of innovation and entrepreneurship incubator platform in colleges and universities are generally faced with problems such as type assimilation, lack of distinctive features, inaccurate function positioning, lack of connotation construction and insufficient fund and service guarantee ${ }^{[2]}$. Outstanding problems can be summarized into three aspects: First, the development direction of the entrepreneurial incubator base is unclear, the function orientation is unclear, and the public welfare and policy bias are insufficient, and it is difficult to achieve the expected goals in terms of talent incubation, entrepreneurial success proportion and economic return. It not only affects students' entrepreneurial enthusiasm, but also damages the image of incubator bases as well as colleges and universities. Second, funding source for entrepreneurial project incubation is narrow, and it is difficult to obtain bank loans. However, funds supported by enterprises and governments are difficult to meet the project incubation needs, leading to entrepreneurship failure. Third, the management system is imperfect, management department's responsibilities are unclear, the limit of authority is unclear, hardware construction and service guarantee are not in place, and transformation of innovation and entrepreneurial achievements are limited, resulting in slow development of college students' entrepreneurship, low participation and insufficient development potential.

\section{Cultivation PATH SELECTION OF INNOVATION AND ENTREPRENEURSHIP TALENTS OF CROSS-BORDER ELECTRONIC COMMERCE}

\section{A. Optimizing double-qualified teaching team of "enterprise expert + teacher"}

The key to cultivating the entrepreneurial talents of cross-border electronic commerce is to have a strong teaching team. The double-qualified teaching team construction should be taken as the key work for the cultivation of innovation and entrepreneurship talents. It should face to society to select team leaders, use various competitions such as cross-border electronic commerce competitions held by the Ministry of Education and innovation and entrepreneurship competitions as a platform to discover outstanding talents, cultivate teaching backbones and enhance team cooperation. In addition, it should set up a special education fund to support teachers to participate in academic research and teaching law research related to innovation and entrepreneurship of cross-border electronic commerce and create opportunities for professional teachers to visit abroad and participate in seminars and training, so as to timely grasp the most cutting-edge academic information and industry developments. Providing time and financial support for full-time teachers who serve temporary positions in cross-border electronic commerce enterprises can make up for the lack of practical experience and improve the level of entrepreneurial guidance. Supporting teachers to conduct in-depth corporate research, undertake high-quality small and medium enterprises projects or participate in entrepreneurial projects can comprehensively enhance the team's professional practice competency. Encouraging teachers to obtain 1-2 Aliexpress gold-medal lecturers and other relevant professional qualification certificates can improve the overall double-qualified teaching team strength. Promoting teachers to actively participate in various social work organized by the government, society and industry associations, serve in relevant academies, associations and research 
associations, and serve as experts and consultants in governments, enterprises or groups can expand their professional and team influence. At the same time, strengthening foreign exchanges and cooperation, hiring experts from cross-border electronic commerce companies, foreign trade industries and training institutions as part-time professors and entrepreneurial instructors and selecting talents without following one set form can promote deep integration of production and education. In addition, social organization experts should be cooperated to analyze job capability requirements, focus on creating Cross-border E-commerce Theory and Practice, net store operation and management, Internet Marketing and other professional core courses, and jointly design teaching links, participate in internship training and make an assessment plan. At the same time, the form of modern mentoring system, expert lectures and theme salons can solve practical difficulties and analyze successful cases for students in cross-border store operations, and implement school-enterprise collaborative education to create a professional teaching team that has professors, enterprise experts and industry backbones, who can understand theories, operate in practice and are proficient in business.

Strengthening the team construction of innovation and entrepreneurship instructors and providing students with comprehensive and systematic service from enrollment, graduation to entrepreneurship are key links to implement cross-border electronic commerce talent cultivation and enhance entrepreneurial competency ${ }^{[3]}$. Developing students' healthy entrepreneurship concepts in various forms such as entrepreneurship guidance courses, expert lectures, psychological consultations and seminars and guiding students to strengthen self-awareness can avoid the herding effect in their career choices. Students should be assisted in career design through theoretical instruction and interview simulation, which can teach them entrepreneurial skills, including entrepreneurial plans writing, entrepreneurial psychological adjustment, entrepreneurial risk management and other contents. Guiding students to think problems independently, judge events objective can make them seek solutions in a positive and persevering spirit. Building a three-dimensional information network, mining, collecting and identifying employment information, eliminating outdated information, blocking the spread of false information, analyzing and forecasting entrepreneurial situations and policies can make students keep abreast of entrepreneurial policies, industry trends and post demands, effectively avoid all kinds of traps (illegal small loans, contracts and intellectual property, etc.), better capture entrepreneurial opportunities and improve the quality of entrepreneurship.

\section{B. Building an integrated industry-education and modular curriculum system}

The construction of curriculum system is an important support for the cultivation of innovation and entrepreneurship talents of cross-border electronic commerce. As an emerging major and interdisciplinary subject, cross-border electronic commerce covers a wide range of subjects and courses. It includes professional courses such as electronic commerce, international trade, business English and marketing. A professional teaching and steering committee consisting of universities, enterprises and industry associations must be established. Based on the school-enterprise collaboration idea, the curriculum system should be put into the framework of professional talents training plan for cross-border electronic commerce, so as to achieve clarified main line, rational connection and integration. Extensively cooperating with well-known third-party electronic commerce platforms and service organizations, and developing partnerships with "100 City School" of Alibaba, "321 E-Business College" of Amazon, Wish and other electronic commerce training institutions ${ }^{[4]}$ can embed relevant courses in the talent cultivation system and build a curriculum system that interfaces with industry and corporate positions.

For students with strong innovation and entrepreneurial willingness and potential, they can be provided with innovative practice classes, which set up project management, supply chain management, internet finance and other courses related to entrepreneurship training. Teaching innovative thinking and innovative skills related to cross-border electronic commerce can cultivate students' awareness of innovation and entrepreneurship, stimulate students' motivation for innovation and entrepreneurship, and strengthen guidance and assistance for students' entrepreneurial process. At the same time, the construction of supporting teaching materials should be strengthened, and the teaching contents should be optimized by writing and publishing auxiliary textbooks of case and training. In the choice of teaching methods, it is necessary to adopt project-based teaching method combined with scenario simulation, case teaching and social research. Students can be recruited to participate in the research team of teachers to conduct topics research. Supporting students to come to bases, enter enterprises, and participate in industry-university-research projects, and encouraging students to participate in various forms of extracurricular practice can achieve the combination of "teaching, learning and practicing".

\section{Constructing a five-tier progressive practice teaching system of "three real three industry"}

The construction of practical teaching system is the most crucial link in the cultivation of applied talents. Strengthening the cultivation of innovation and entrepreneurship talents must accord to the cultivation of industry cognitive competency, professional comprehensive competency and innovative practice competency, so as to construct a comprehensive, three-dimensional and progressive practice teaching network (as shown in the Fig.1) of "three real three industry" ${ }^{[5]}$. Therefore, it can realize "doing by learning, learning by practicing and innovating by doing", cultivate innovative thinking and innovative ideas, create students' innovative competency and innovative advantages, and provide a solid guarantee for implementation of innovation and entrepreneurship talent cultivation mode. 

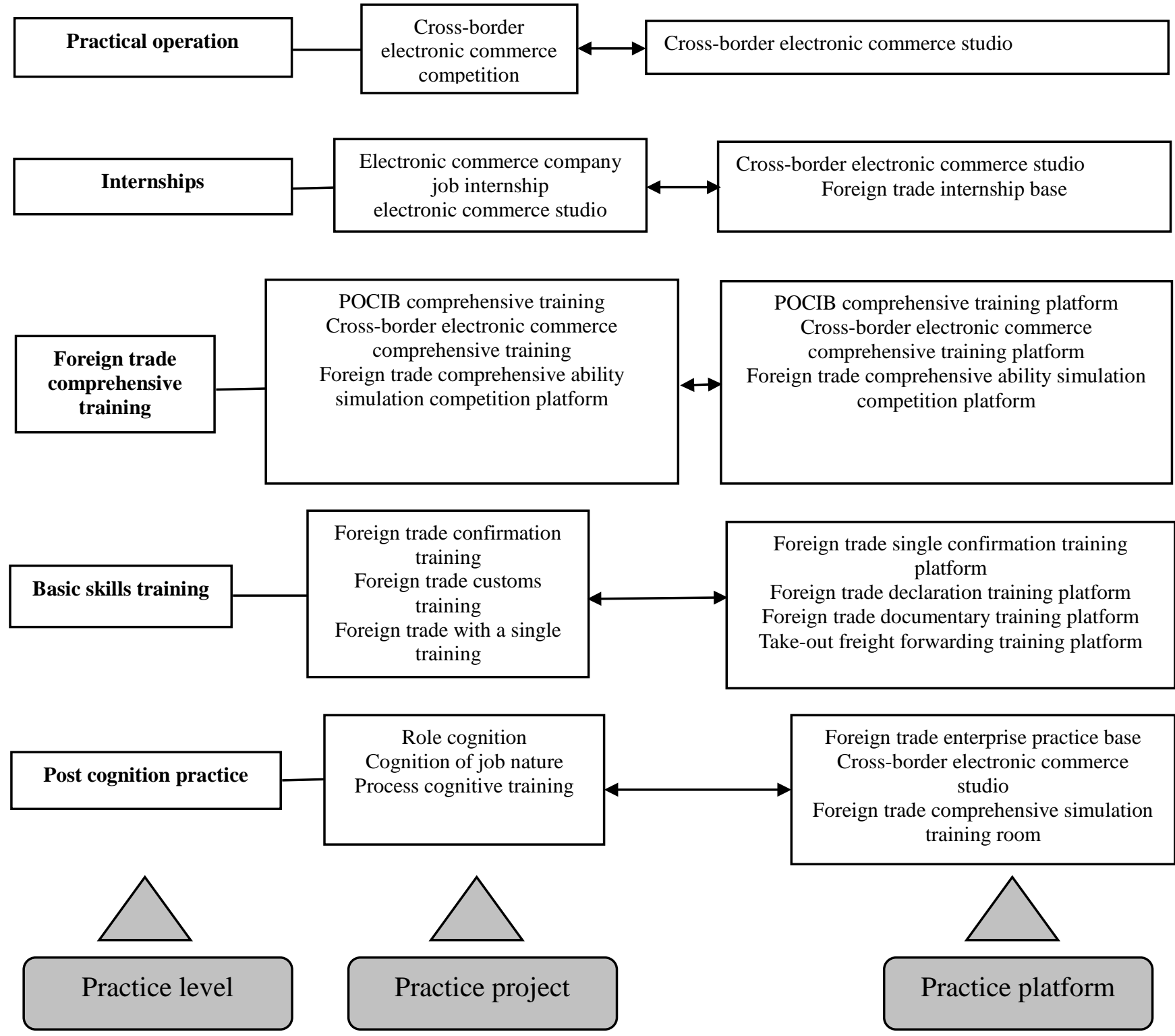

Fig. 1 Five-tier progressive, "three real three industry" practical teaching system

"Three real" means internship, practical training and practical operation. Students' post cognition, professional simulation and practical operation competency should be cultivated and trained step by step. "Three industries" means professional skills certificates, employment qualification certificates and graduation thesis. Acquiring foreign trade salesman and storekeeper certificates can improve the upgrading of students' post skills. "Five-tier progressive" includes post cognition internship of foreign trade, post-skills training, comprehensive simulation training of foreign trade, enterprise post-training and actual combat operations, and it links practical teaching parts at various stages with successive progressive advancement. Training internships adopt the method of concentration and combination of reality and virtuality. "Virtuality" refers to simulation training, which takes virtual projects and simulation training platforms. In the third and fourth semesters, comprehensive training of cross-border electronic commerce can be set and comprehensive skills training platform software of international trade can be used to realize network simulation and improve comprehensive skills of cross-border electronic commerce operations comprehensively, systematically and efficiently. "Reality" refers to real work tasks introduced by enterprises. In the fifth and sixth semester, students can be arranged into foreign trade enterprises for internship, to participate in cross-border electronic commerce competitions, to enter foreign trade positions, and to accept real work tasks and complex work environments. In the seventh and eighth semester, students can be arranged into cross-border electronic commerce studio to use electronic commerce platforms such as DHgate and Aliexpress for practical operations, use "OCALE platform" to interface with offline real product providers, online real customers and cross-border electronic commerce operators, complete real tasks in real transaction platforms of 
cross-border electronic commerce and accomplish real trade. If the project is mature, students can enter the university science park, apply for an incubator fund, and enter into the link of industry incubator and cultivation.

\section{Strengthening the construction of innovation and entrepreneurship incubator platform in colleges and universities}

The construction of innovation and entrepreneurship incubator platform in colleges and universities should rely on the advantages of disciplines, scientific research and talents, innovate system and mechanism, highly integrate high-quality resources of governments, universities, industries and industry associations, deepen the integration of production and education, and promote the organic connection of education chain and talent chain with industry chain and innovation chain, so as to solve "drawbacks" that restrict the transformation and application of scientific research achievements in colleges and universities as soon as possible, and gradually form the operation mode of innovation and entrepreneurship incubator platform based on "school-dominant, student-independent, teacher-participated, enterprise-involved and government-supported"[6] and the cultural innovation and entrepreneurial culture atmosphere of "social affirmation, group policy and tolerance".

The innovation and entrepreneurship incubator platform in colleges and universities has five attributes, i.e., internship base, scientific research base, training base, enterprise service base and innovation and entrepreneurship base. It cannot appear completely in the form of social business incubator, but must return to the essence of education, which is in line with school-running positioning and implementation of talent cultivation goal, so as to promote discipline professional development, coordinate scientific research innovation, serve the society and inherit innovation and entrepreneurship culture. Taking the entrepreneurial incubator base of cross-border electronic commerce in colleges and universities as an example, its core task is talent cultivation, entrepreneurial service and enterprise service. In terms of talent cultivation, cultivating innovation and entrepreneurship talents and fostering automatic entrepreneurship by teachers and students should be taken as long-term development goals, and cross-border electronic commerce courses should be combined to form relevant cross-border electronic commerce training programs to provide services for curriculum teaching. Students should be provided with a realistic cross-border electronic commerce learning environment. The basic equipment of the incubator center should be used to provide skills practicing places for students participating in various skill competitions or innovation and entrepreneurship competitions of cross-border electronic commerce. In terms of entrepreneurial service, it aims to provide entrepreneurial teams with entrepreneurship incubator services such as coaching, training, project conversion docking and financing channels. Determining the key cultivation and incubator direction can provide guarantee for entrepreneurship education, resource integration, project aggregation, sharing and cooperation, transformation and docking as well as management innovation, and focus on fostering "small but specialized, small but refined" innovation and entrepreneurship enterprises with core competitiveness.
Innovation and entrepreneurship groups should be provided with services, i.e., the latest policy advice, legal services, entrepreneurial guidance of cross-border electronic commerce entrepreneurship, entrepreneurial places, equipment and project docking service. Entrepreneurial projects lacking funds should be provided with financing channels. In terms of enterprises services, it should be based on promoting local economic development and providing services to regional enterprises. Division of management departments' responsibilities should be implemented to establish cross-border electronic commerce platforms for relevant enterprises in the region and provide services such as registration, optimization and promotion of stores. Enterprises with cross-border trade platforms should be provided with services such as order receiving, customs declaration, logistics, customer maintenance, etc. Enterprise personnel should be provided with cross-border electronic commerce training and learning to realize personnel retraining and enhance the business level and work innovation of enterprise employees.

\section{E. The establishment of system and mechanism is an important guarantee to realize the competency cultivation goal of innovation and entrepreneurship}

Institutional factors act as the baton of innovation and entrepreneurial activities and teaching in colleges and universities, and the flexible and scientific talent cultivation system and management mechanism are the fundamental guarantee for the smooth implementation of innovation and entrepreneurship training programs of cross-border electronic commerce. From the perspective of teaching team construction, it is necessary to establish a "double-entry" school-enterprise cooperation and education mechanism ${ }^{[7]}$ of "teachers enter the enterprise and entrepreneurs into the classroom", formulate the qualification evaluation, post-appointment and daily workload calculation methods for double-qualified teachers, implement the system of innovation and entrepreneurship tutors, define the responsibilities and authorities of entrepreneurial tutors, construct an evaluation mechanism for the selection, motivation, and guidance of innovative instructors, break bottleneck constraints such as insufficient motivation of instructors and unclear target responsibilities, and promote the standardization and institutionalization of innovation and entrepreneurship mentoring system. From the perspective of students, it is necessary to establish a flexible teaching management system, promote class organization and learning team organization in parallel, strengthen comprehensive evaluation of team members' cooperation competency in all aspects of teaching, team innovation and entrepreneurship activities and competitions, and implement flexible academic system and credit replacement system of post-practice. Only by establishing and perfecting these mechanisms can the unity and integration of interests and goals for universities, enterprises, teachers and students be achieved, so as to promote the goal of innovation and entrepreneurship competency with school-enterprise integration, teacher-student collaboration and working-learning alternation.

\section{SUMMARY}

Under the macro background of "Internet plus foreign trade" and "mass entrepreneurship and mass innovation", the 
innovation and entrepreneurship talents cultivation of cross-border electronic commerce in colleges and universities has a good environmental foundation and policy guarantee. Through constructing double-qualified teaching team, building curriculum system, improving progressive and all-round practical teaching system and building entrepreneurship incubator bases, the innovation and entrepreneurship talents cultivation of cross-border electronic commerce in colleges and universities can be provided with clear ideas, measures and cultivation path choices, universities, and provide a path for the cultivation of innovative entrepreneurs. Using software and hardware construction and institutional innovation can effectively crack the bottleneck constraints of insufficient cultivation of cross-border electronic commerce talents, mismatch between talents supply and demand, and insufficient competency for innovation and entrepreneurship talents of cross-border electronic commerce, and promote the government, colleges and universities, enterprises, teachers and students to benefit from a win-win situation. It is of great significance to develop and grow cross-border electronic commerce industry as well as transfer and upgrade traditional foreign trade industry, and it has a far-reaching impact on promoting the integration of industry and education and realizing talents cultivation and social service functions of colleges and universities.

\section{REFERENCES}

[1] Research on the Cultivation Path of Cross-Border Electric Commerce of International Trade Major in Colleges and Universities[J]. Wang Junling, Modern Economic Information, 2019 (06).

[2] Research on the Construction of Innovation and Entrepreneurship Incubator Base of Cross-border Electronic Commerce in Colleges and Universities[J]. Xiao Jingying, 2018 (10).

[3] Research on Training Teaching Mode of Open Cross-border Electronic Commerce [J]. Huo Guzheng, Market Forum. 2017(04).

[4] Bottlenecks and Countermeasures for the Development of Entrepreneurial Incubator Base Construction Mode[J]. Xi Ning, Business Talent, 2018(10).

[5] Research on the Construction of Cross-border Electronic Commerce Training Base Based on Innovation and Entrepreneurship Orientation[J]. Lv Hongjing, Electronic Commerce, 2017(01).

[6] Research on Entrepreneurial Incubator Base of College Students[J]. Xu Yan, Science and Technology Journal, 2018 (10).

[7] Research on the Combination of Cross-border Electronic Commerce Courses and College Students' Innovation and Entrepreneurship Education[J]. Liu Chao, China Education of Light Industry, 2017(02). 